\title{
Nota Científica: Teste de aceitação de bebida mista de soja e amora
}

Scientific Note: Acceptance test of a mixed soybean and mulberry drink

\section{Autores | Authors}

Maíra Rodrigues ULIANA

Universidade Estadual Paulista (UNESP) Faculdade de Ciências Agronômicas Departamento de Gestão e Tecnologia Agroindustrial Laboratório de Bebidas Botucatu/SP - Brasil e-mail:mruliana@gmail.com

\section{凶 Waldemar Gastoni VENTURINI}

\section{FILHO}

Universidade Estadual Paulista (UNESP) Faculdade de Ciências Agronômicas Departamento de Gestão e Tecnologia Agroindustrial Caixa Postal: 237 CEP: 18610-307 Botucatu/SP - Brasil e-mail:venturini@fca.unesp.br

\section{Lis Rodrigues ULIANA}

Universidade de São Paulo (USP) Escola Superior de Agricultura "Luiz de Queiroz"

Piracicaba/SP - Brasil e-mail: Iruliana@hotmail.com

Autor Correspondente / Corresponding Author

Recebido / Received: 17/08/2010 Aprovado / Approved: 03/0/2012 Publicado / Published: jun./2012

\section{Resumo}

O objetivo deste trabalho consistiu em elaborar e avaliar a aceitação de bebida mista de extrato hidrossolúvel de soja (EHS) e suco de amora (SA). As bebidas, produzidas com diferentes proporções de EHS e SA (1:1; 1:1,5; $1: 2 \mathrm{~m} / \mathrm{m}$ ), e diferentes concentrações de sólidos solúveis (10, 12 e $14{ }^{\circ}$ Brix), foram analisadas sensorialmente e seus resultados foram submetidos à análise de variância e regressão. As diferentes proporções de EHS e SA nas bebidas produzidas interferiram no aroma e na aparência das bebidas; porém, não existiu uma relação direta entre essas proporções e a aceitabilidade desses atributos. O teor de sólidos solúveis, entretanto, influenciou o sabor e a impressão global. A preferência dos provadores, tanto no sabor como na impressão global, recaiu nas bebidas mais doces, havendo uma relação direta entre o teor de açúcar e a aceitação. Todas as bebidas formuladas foram aprovadas pela equipe de provadores.

Palavras-chave: Bebida não alcoólica; Análise sensorial; Escala hedônica.

\section{Summary}

The purpose of this study was to prepare and evaluate the acceptability of a mixed hydrosoluble soybean extract (EHS) and mulberry juice (SA) drink. The drinks, made with different proportions of EHS and SA (1:1, 1:1.5 and 1:2 w/w) and different concentrations of soluble solids (10, 12 and $14^{\circ}$ Brix), were analyzed by a sensory evaluation and the results submitted to an analysis of variance and regression. The different proportions of EHS and SA interfered in the beverage aroma and appearance, but there was no direct relationship between these proportions and acceptability of the attributes. However, the soluble solids content affected the taste and overall impression. The preference of the panellists, both with respect to flavour and overall impression, was for the sweeter drinks, and there was a direct relationship between the sugar content and acceptance. All the beverages were approved by the panellists.

Key words: Non alcoholic beverage; Sensory analysis; Hedonic scale. 


\section{Introdução}

De acordo com o Decreto 6.871 (BRASIL, 2009), refresco misto ou bebida mista de frutas, de extratos vegetais ou de frutas e extratos vegetais é a bebida obtida pela diluição em água potável da mistura de suco de fruta, da mistura de extrato vegetal, ou pela combinação de ambos.

O EHS (extrato hidrossolúvel de soja) é o produto obtido por extração aquosa dos sólidos solúveis dos grãos de soja, o qual consiste de uma suspensão de proteínas e de carboidratos, de uma emulsão de lipídeos e de uma solução de alguns minerais (LIU, 1999).

O consumo do EHS vem aumentando, visivelmente, impulsionado pelo novo enfoque da soja, relacionado com a prevenção de algumas doenças. Além disso, a soja apresenta versatilidade para utilização na forma direta ou na elaboração de outros produtos, como sorvetes, análogos de leite condensado e creme de leite, bebidas e em mistura com inúmeras outras matérias-primas (GUERREIRO, 2006; RODRIGUES et al., 2003).

Segundo Torres-Penaranda e Reitmeier (2001), a soja e seus subprodutos têm um sabor característico, que é desagradável ao paladar da população ocidental. Diversos autores relataram que o sabor característico da soja, descrito de forma geral como rançoso ou de feijão cru, é proveniente da auto-oxidação dos ácidos graxos poli-insaturados ou da ação enzimática das lipoxigenases, que formam os compostos voláteis responsáveis pelo sabor desagradável (LIU, 1997; MACLEOD et al., 1988; TORRES-PENARANDA et al., 1998).

A soja é considerada um alimento funcional porque, além de funções nutricionais básicas, produz efeitos benéficos à saúde, reduzindo os riscos de algumas doenças crônicas e degenerativas. É rica em proteínas de boa qualidade, possui ácidos graxos poliinsaturados e compostos fitoquímicos, como isoflavonas, saponinas e fitatos, dentre outros. Também é uma fonte de minerais, como cobre, ferro, fósforo, potássio, magnésio, manganês e vitaminas do complexo B (CARRÃO-PANIZZI e MANDARINO, 1998; EMBRAPA, 2008a, b; KAWAGA, 1995).

Os sucos de fruta acrescidos de produtos de soja apresentam potencial de crescimento, pois conciliam as características sensoriais desejáveis das frutas com as propriedades funcionais da soja (ALIMENTOS, 2000). Segundo Krones (2002), no Brasil, o crescimento em volume de vendas de bebidas à base de proteína de soja foi de 104\% no primeiro semestre de 2002.

A combinação EHS com suco de fruta contribui sensorialmente para a aceitação da soja como bebida, pois minimiza sensivelmente o impacto negativo do seu sabor característico, proveniente de certos componentes da leguminosa (MORAIS e SILVA, 1996).
Rodrigues et al. (2003) evidenciaram que bebidas formuladas com polpa de pêssego e EHS, além de importantes fontes de isoflavonas, melhoram a aceitação sensorial da soja. Mercaldi (2006) também concluiu que a adição de suco graviola ao EHS foi significativa na melhora da aceitação da bebida.

Hassimotto (2005), estudando amora in natura e em polpa congelada, verificou elevada atividade antioxidante. Além disso, identificou os compostos associados a essa atividade e encontrou a presença de flavonoides.

O uso do SA (suco de amora) em bebida de soja, além de contribuir para mascarar o sabor do EHS, melhora a cor e acrescenta compostos bioativos à bebida.

A elaboração de bebida de soja acrescida de SA é um trabalho original, pois não foi encontrado qualquer artigo científico sobre esse tema.

Em função do exposto, o objetivo deste estudo consiste em produzir e analisar sensorialmente bebidas mistas de extrato hidrossolúvel de soja e suco de amora, com diferentes proporções de EHS/SA e teores de sólidos solúveis.

\section{Material e métodos}

\subsection{Planejamento experimental}

O delineamento experimental foi definido em nove tratamentos e duas repetições. Os tratamentos analisados sensorialmente foram produzidos com diferentes proporções de EHS e SA $(1: 1 ; 1: 1,5 ; 1: 2$, respectivamente, massa:massa) e os diferentes teores de sólidos solúveis (10, 12 e $14^{\circ}$ Brix).

\subsection{Material}

\subsubsection{Matérias-primas}

O cultivar de soja selecionado para o presente estudo foi o BRS 213, obtido por doação da EMBRAPASoja.

A amora utilizada foi a do gênero Morus, colhida em 2007, no município de Botucatu-SP. O resultado obtido na colheita foi de $50 \%$ de frutos maduros (frutos de coloração preta que afundavam na água de lavagem) e $50 \%$ de frutos imaturos (frutos de coloração vermelha que flotavam na água de lavagem). Em função disto, para a produção do SA deste trabalho, foram utilizadas 50\% de amoras imaturas e 50\% de amoras maduras.

Após a colheita, as amoras passaram por limpeza/ seleção e foram armazenadas em freezer doméstico $\left(-18^{\circ} \mathrm{C}\right)$ até a sua utilização.

Foram utilizados, também, açúcar cristal comum e pectina cítrica, ambos obtidos por doação. O açúcar foi usado como adoçante e a pectina cítrica, como estabilizante da mistura EHS e SA. 


\subsection{Métodos}

\subsubsection{Produção do EHS}

Para a produção do EHS, foi utilizada uma máquina de extração de EHS (vaca mecânica) com capacidade de 50 L/batelada. A proporção de soja:água foi de 1:10, conforme recomendação do fabricante.

A soja com casca foi limpa (lavagem em água corrente por aproximadamente um minuto) e introduzida no moinho da vaca mecânica para a extração do EHS. Essa operação foi feita na presença de água quente $\left(92 \pm 5^{\circ} \mathrm{C}\right)$.

Após a moagem, a mistura (EHS + resíduo sólido) foi mantida quente $\left(92 \pm 5^{\circ} \mathrm{C}\right)$ por 10 min na caldeira da vaca mecânica e, posteriormente, filtrada (tecido sintético de malha fina tipo voil), para a separação do EHS e do resíduo sólido (okara).

\subsubsection{Produção do $S A$}

O SA foi produzido obedecendo-se à proporção $50 \%$ de amoras maduras e 50\% de amoras imaturas, conforme o resultado obtido na colheita da fruta.

Para a produção do SA, foi utilizada uma prensa hidráulica, na qual a fruta, envolvida em tecido sintético de malha fina do tipo voil, permaneceu por oito minutos à pressão de $60000 \mathrm{kgf} \cdot \mathrm{m}^{-2}$ ( $5 \mathrm{t}$, indicação do manômetro). O bagaço da fruta foi retido pelo voil e o suco drenado pela parte inferior da prensa.

\subsubsection{Produção da bebida mista de EHS e de SA}

O EHS ainda quente (calor residual do processamento) foi homogeneizado em liquidificador industrial por 5 min com $0,50 \%$ de pectina cítrica. Esta foi previamente homogeneizada em um pequeno volume de EHS (10\% do total).

Após a estabilização com a pectina, o EHS foi misturado ao SA, no liquidificador, por mais $5 \mathrm{~min}$. As quantidades relativas de EHS:SA foram definidas pelos tratamentos $(1: 1 ; 1: 1,5 ; 1: 2)$. A bebida mista obtida teve seu teor de sólidos solúveis mensurado e depois corrigido para 10,12 e $14^{\circ}$ Brix, conforme previsto nos tratamentos. Para essa correção, utilizou-se o seguinte balanço de massa (Equação 1).

Bebida mista + Açúcar = Bebida mista final

$B_{1} \times M_{1}+B_{2} \times M_{2}=B_{3} \times M_{3}$

onde: $B_{1}=$ Brix da mistura de EHS e $S A ; M_{1}=$ massa da mistura de EHS e SA; $B_{2}=$ Brix do açúcar cristal; $\mathrm{M}_{2}=$ massa do açúcar cristal; $\mathrm{B}_{3}=$ Brix da bebida mista final; $M_{3}=$ massa dabebida mista final.

Na sequência, as bebidas mistas foram envasadas em garrafas de vidro branco transparente de $500 \mathrm{~mL}$, esterilizadas e fechadas com rolhas metálicas rosqueáveis esterilizadas.

Após o envase, as bebidas mistas foram pasteurizadas em banho-maria à temperatura de $90 \pm 3{ }^{\circ} \mathrm{C}$ durante $30 \mathrm{~min}$.

O processamento da bebida mista está descrito resumidamente na Figura 1.

\subsection{Análises sensoriais}

As bebidas mistas de EHS e SA foram avaliadas sensorialmente por meio da aplicação de teste de aceitação por escala hedônica (BRASIL, 2005). Utilizou-se uma escala estruturada de nove pontos $(1$ = desgostei extremamente e 9 = gostei extremamente), pela qual foram avaliados três atributos (aparência, aroma e sabor) e a impressão global (BRASIL, 2005).

As amostras foram codificadas utilizando-se números de três dígitos ao acaso, servidas aleatoriamente em taças de vidro, à temperatura de refrigeração. A equipe sensorial contou com 58 provadores não treinados, sendo constituída por funcionários e alunos pertencentes à Faculdade de Ciências Agronômicas da UNESP, Campus de Botucatu (BRASIL, 2005).

Os provadores foram instruídos a enxaguar a boca com água entre as provas das amostras, para evitar a possível interferência de sabor residual das bebidas.

\subsection{Análise estatística}

$\mathrm{Na}$ análise sensorial, feita pelo teste de escala hedônica, os dados obtidos foram submetidos à análise de variância e à posterior análise de regressão, pois os tratamentos são dependentes entre si (GOMES, 1976). O programa estatístico utilizado foi o programa Statistical Analysis System (SAS, 2001).

\section{Resultados e discussão}

\subsection{Teste de aceitação - escala hedônica}

\subsubsection{Atributo aparência}

A partir dos resultados da análise de variância (Tabela 1), pode-se observar que os diferentes teores de sólidos solúveis (B) não interferiram na aparência das bebidas (Tabela 1); esse fato já era esperado, pois a adição de açúcar, nas quantidades utilizadas, não influencia na cor e na turbidez da bebida final.

As proporções EHS/SA $(1: 1 ; 1: 1,5 ; 1: 2)$ interferiram na aparência das bebidas $(P)$, cuja diferença foi percebida pelos provadores (Tabela 1). Como a variável é quantitativa, realizou-se a análise de regressão polinomial (Tabela 2). 


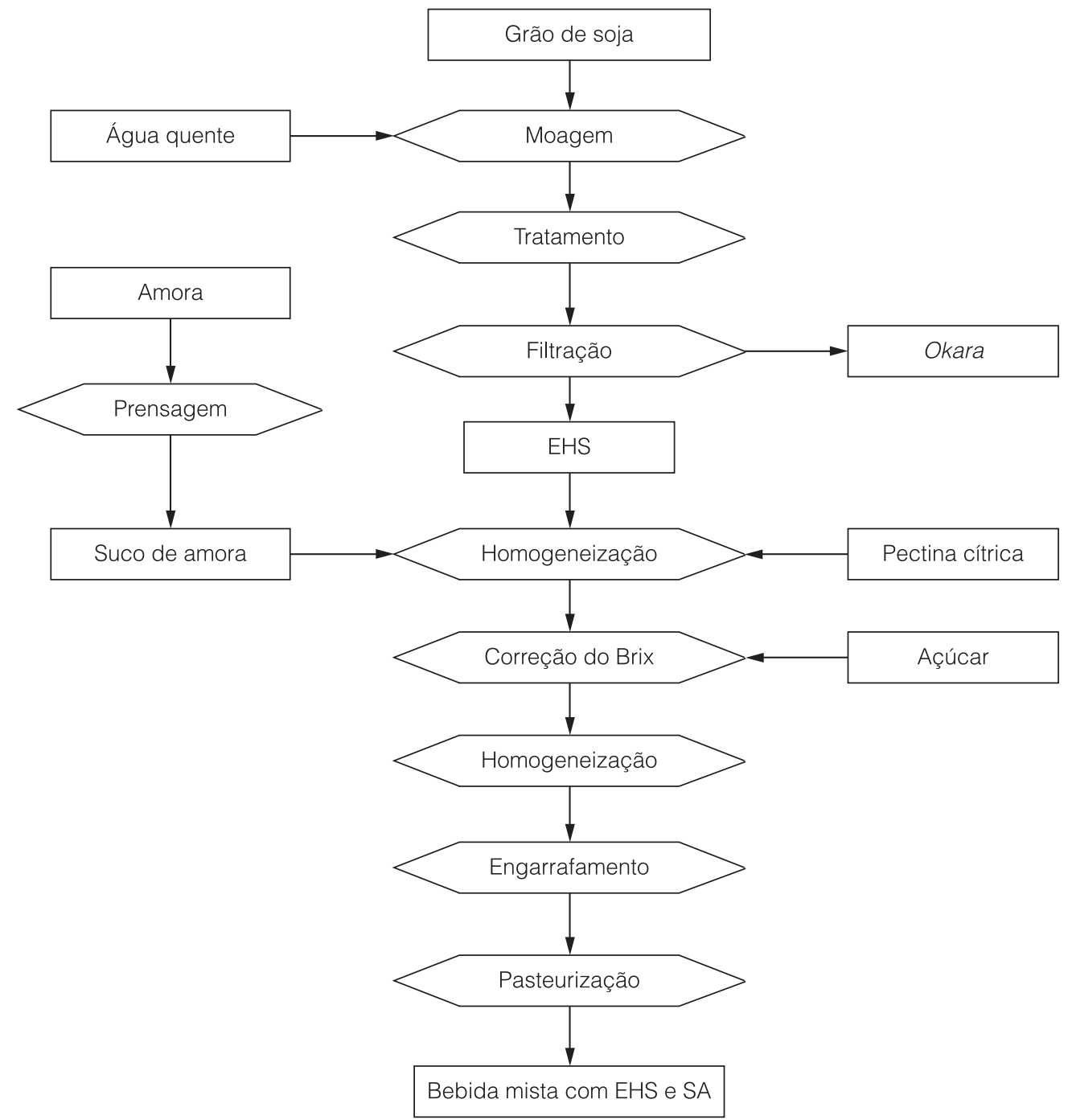

Figura 1. Fluxograma de produção da bebida mista de EHS e SA.

Tabela 1. Análise de variância para o resultado da análise sensorial do atributo aparência.

\begin{tabular}{lcccc}
\multicolumn{1}{c}{ Causa de variação } & GL & SQ & F & Pr > F \\
Blocos & 1 & 0,26 & 3,13 & 0,11 \\
Proporção EHS/SA (P) & 2 & 0,90 & $5,48^{*}$ & 0,03 \\
Sólidos solúveis (B) & 2 & 0,04 & 0,27 & 0,77 \\
Interação P × B & 4 & 0,05 & 0,15 & 0,96 \\
Resíduo & 8 & 0,65 & - & - \\
Total & 17 & 1,90 & - & - \\
\hline
\end{tabular}

*Significativo.

Tabela 2. Análise de regressão para as diferentes proporções EHS/SA, referente ao atributo aparência.

\begin{tabular}{lrccc}
\multicolumn{1}{c}{$\begin{array}{c}\text { Causa de } \\
\text { variação }\end{array}$} & GL & SQ & F & $\begin{array}{c}\text { Coef. } \\
\text { determ. }\end{array}$ \\
Proporção EHS/SA (P) & 2 & 0,90 & 6,69 & 1,00 \\
Resíduo & 15 & 1,01 & - & - \\
Total & 17 & 1,90 & - & - \\
\hline
\end{tabular}

O efeito das diferentes proporções de EHS/SA na aparência da bebida foi diferenciado, representado pela Equação 2 e pela Figura 2.

$\mathrm{y}_{\mathrm{i}}=8,3150-1,7592 \mathrm{x}_{\mathrm{i}}+0,4575 \mathrm{x}_{\mathrm{i}}^{2}$

em que: $x_{i}=$ proporção EHS/SA $i ; y_{i}=$ resposta à análise sensorial do atributo aparência (nota) em função das diferentes proporções de EHS/SA i.

As bebidas com maior proporção de SA apresentaram, visualmente, coloração mais intensa. Contudo, a Figura 2 mostra que a preferência dos provadores pelas bebidas não tem uma relação direta com a intensidade de cor. Portanto, esses resultados não estão claros suficientemente para que se possa fazer uma afirmação sobre qual a melhor proporção para o atributo aparência.

Examinando-se as médias das notas da análise sensorial para aparência (Tabela 3), pode-se observar que o grupo de provadores aprovou de uma maneira 
Teste de aceitação de bebida mista de soja e amora

ULIANA, M.R. et al.

Tabela 3. Médias das notas da análise sensorial para os atributos aparência, aroma e sabor, e impressão global.

\begin{tabular}{|c|c|c|c|c|c|}
\hline \multicolumn{2}{|c|}{ Tratamentos } & \multirow{2}{*}{$\begin{array}{c}\text { Aparência } \\
7,0\end{array}$} & \multirow{2}{*}{$\begin{array}{c}\text { Aroma } \\
5,9\end{array}$} & \multirow{2}{*}{$\begin{array}{c}\text { Sabor } \\
5,6\end{array}$} & \multirow{2}{*}{$\begin{array}{c}\text { Impressão global } \\
6,0\end{array}$} \\
\hline & B10 & & & & \\
\hline $1: 1$ & B12 & 7,0 & 5,9 & 6,6 & 6,7 \\
\hline & B14 & 7,0 & 6,3 & 7,5 & 7,4 \\
\hline \multirow{3}{*}{$1: 1,5$} & B10 & 6,6 & 5,6 & 5,1 & 5,7 \\
\hline & B12 & 6,6 & 5,6 & 6,1 & 6,4 \\
\hline & B14 & 6,7 & 5,6 & 6,9 & 6,8 \\
\hline \multirow{3}{*}{$1: 2$} & B10 & 7,0 & 6,0 & 5,1 & 5,6 \\
\hline & B12 & 7,2 & 6,2 & 6,5 & 6,7 \\
\hline & B14 & 7,2 & 6,7 & 7,6 & 7,4 \\
\hline
\end{tabular}

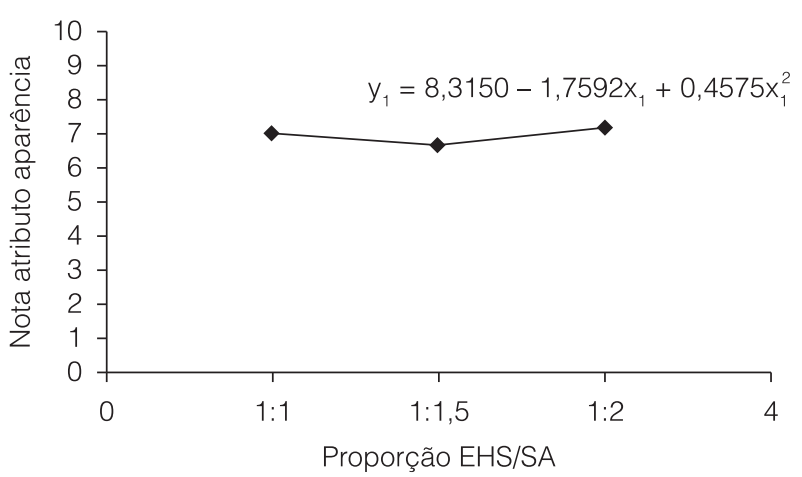

Figura 2. Efeito das diferentes proporções EHS e SA na aparência da bebida mista.

geral as bebidas para tal atributo, tendo suas notas em torno de 6,6 a 7,2.

\subsubsection{Atributo aroma}

Conforme a análise de variância (Tabela 4), as diferentes concentrações de sólidos solúveis (B) não interferiram no aroma da bebida final, uma vez que a sacarose e seus produtos de hidrólise (glicose e frutose) não são moléculas voláteis.

As diferentes proporções EHS/SA interferiram significativamente no aroma da bebida (P) (Tabela 4). Na medida em que a variável é quantitativa, realizou-se a análise da regressão polinomial (Tabela 5).

As diferentes proporções EHS/SA interferiram significativamente no aroma da bebida (Figura 3; Equação 3). Porém, esses resultados mostram que a preferência dos provadores não guarda uma relação direta com a concentração de SA na bebida mista.

$y_{i}=7,4317-1,9433 x_{i}+0,5233 x_{i}^{2}$

Em que: $x_{i}=$ proporção EHS/SA $i ; y_{i}=$ resposta à análise sensorial de aroma (nota) em função das diferentes proporções de EHS/SA i.

O aumento das proporções de SA na formulação resulta em bebida mais pobre em odor de soja - o que é uma vantagem -, visto que a maioria das pessoas não
Tabela 4. Análise de variância para o resultado da análise sensorial do atributo aroma.

\begin{tabular}{lcccc}
\multicolumn{1}{c}{ Causa de variação } & GL & SQ & F & Pr > F \\
Blocos & 1 & 0,06 & 0,59 & 0,46 \\
Proporção EHS/SA (P) & 2 & 1,36 & $6,83^{*}$ & 0,02 \\
Sólidos solúveis (B) & 2 & 0,48 & 2,39 & 0,15 \\
Interação P × B & 4 & 0,28 & 0,71 & 0,61 \\
Resíduo & 8 & 0,80 & & \\
Total & 17 & 2,99 & & \\
\hline
\end{tabular}

*Significativo.

Tabela 5. Análise de regressão para proporção EHS/SA, referente ao atributo aroma.

\begin{tabular}{lrrcc}
\multicolumn{1}{c}{$\begin{array}{c}\text { Causa de } \\
\text { variação }\end{array}$} & GL & SQ & F & $\begin{array}{c}\text { Coef. } \\
\text { determ. }\end{array}$ \\
Proporção EHS/SA (P) & 2 & 1,09 & 10,13 & 0,80 \\
Resíduo & 15 & 1,62 & - & - \\
Total & 17 & 2,72 & - & - \\
\hline
\end{tabular}

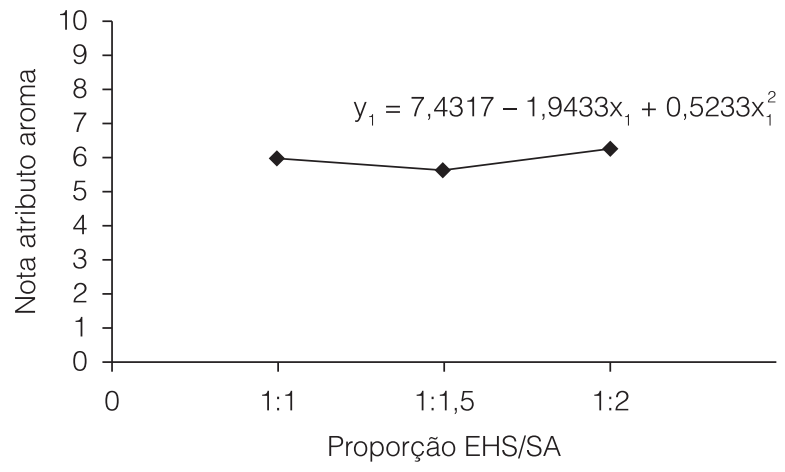

Figura 3. Efeito das diferentes proporções EHS e SA no aroma da bebida mista.

aprecia o odor dessa leguminosa (MORAIS e SILVA, 1996). Contudo, o ganho de aroma nas bebidas produzidas com maior proporção de SA foi baixo.

Examinando-se as médias das notas da análise sensorial para o aroma (Tabela 3), pode-se observar que o grupo de provadores atribuiu notas de 5,6 ("não gostou; nem desgostou") a 6,7 ("gostou ligeiramente") para as bebidas formuladas. 
Rodrigues (2003) obteve valores semelhantes, entre 5,92 e 6,67, para o atributo aroma em bebidas formuladas com EHS e polpa de pêssego, e avaliadas pelo teste de aceitação escala hedônica (não estruturada de nove pontos). No entanto, Soares Júnior et al. (2010) produziram bebidas de extrato de soja saborizadas com polpa de maracujá e açúcar, e alcançaram valores mais satisfatórios (7,92 - gostei muito) para o atributo aroma (teste de escala hedônica estruturada de nove pontos).

\subsubsection{Sabor}

As diferentes proporções de EHS/SA (P) não interferiram no sabor das bebidas (Tabela 6), isto é, se houve alteração de sabor, esta foi suficientemente pequena a ponto de não ser percebida pela equipe de provadores.

As diferentes concentrações de sólidos solúveis (B) interferiram no sabor das bebidas (Tabela 6). Na medida em que a variável é quantitativa, realizou-se a análise da regressão polinomial (Tabela 7 ).

A Equação (4) e a Figura 4 representam o modelo.

$\mathrm{y}_{\mathrm{i}}=4,2456+1,0442 \mathrm{x}_{\mathrm{i}}$

em que: $x_{i}=$ sólidos solúveis $i ; y_{i}=$ resposta à análise sensorial de sabor (nota) em função dos teroes de sólidos solúveis i.

Os diferentes teores de sólidos solúveis interferiram no sabor das bebidas. A Figura 4 mostra que a preferência da bebida pela equipe de provadores está diretamente relacionada com a sua doçura, dentro da faixa de Brix estudada.

Examinando-se as médias das notas da análise sensorial para o atributo sabor (Tabela 3), pode-se

Tabela 6. Análise de variância para o resultado da análise sensorial do atributo sabor.

\begin{tabular}{lcrcc} 
Causa de variação & GL & SQ & F & Pr > F \\
Blocos & 1 & 0,04 & 0,20 & 0,66 \\
Proporção EHS/SA (P) & 2 & 0,80 & 2,01 & 0,20 \\
Sólidos solúveis (B) & 2 & 13,12 & $33,09^{*}$ & 0,00 \\
Interação P × B & 4 & 0,24 & 0,30 & 0,87 \\
Resíduo & 8 & 1,59 & - & - \\
Total & 17 & 15,79 & - & - \\
\hline
\end{tabular}

*Significativo.

Tabela 7. Análise de regressão para sólidos solúveis, referente ao atributo sabor.

\begin{tabular}{lrrcc}
\multicolumn{1}{c}{$\begin{array}{c}\text { Causa de } \\
\text { variação }\end{array}$} & GL & SQ & F & $\begin{array}{c}\text { Coef. } \\
\text { determ. }\end{array}$ \\
Sólidos solúveis (B) & 1 & 13,08 & 77,41 & 0,99 \\
Resíduo & 16 & 2,70 & - & - \\
Total & 17 & 15,79 & - & - \\
\hline
\end{tabular}

observar que o grupo de provadores "não gostou; nem desgostou" (médias entre 5,1 e 5,6) das bebidas produzidas com $10{ }^{\circ B r i x ~ g o s t o u ~ " l i g e i r a m e n t e " ~(m e ́ d i a s ~}$ entre 6,1 e 6,6 ) das com $12^{\circ}$ Brix e gostou "regularmente" (médias entre 6,9 e 7,6) das bebidas com $14^{\circ}$ Brix.

Soares Júnior et al. (2010) avaliaram bebidas mistas de EHS com polpa de maracujá e açúcar também pelo teste de escala hedônica estruturada de nove pontos e obtiveram média de 7,91 para o atributo sabor, média essa próxima às das bebidas produzidas com $12^{\circ}$ Brix. Diversamente, Rodrigues (2003) estudou bebidas formuladas com EHS e polpa de pêssego, e observou notas de 4,88 a 6,37 (trabalhando com escala hedônica não estruturada de nove pontos).

Branco et al. (2007) avaliaram pelo teste da escala hedônica (estruturada com sete pontos) bebidas de soja acrescidas de polpa de morango e sacarose, e observaram que as bebidas com $25 \%$ de polpa de morango e $15 \%$ de adição de sacarose obtiveram as melhores médias $(6,47)$ para 0 atributo sabor. Esses autores também concluíram que à medida que se aumentava a concentração de açúcar nas bebidas formuladas, a aceitação para o atributo sabor também aumentava. Assim como Rodrigues (2003), que estudou bebidas de EHS acrescidas com polpa de pêssego e verificou que porcentuais crescentes de açúcar (dentro da faixa estudada) aumentam a aceitação da bebida para o atributo sabor, tal aumento da aceitação também foi observado no presente trabalho.

\subsubsection{Impressão global}

As diferentes proporções de EHS/SA (P) não interferiram na impressão global das bebidas. Porém, as diferentes concentrações de sólidos solúveis (B) interferiram na impressão global da bebida (Tabela 8). Na medida em que a variável é quantitativa, realizou-se a análise da regressão polinomial (Tabela 9).

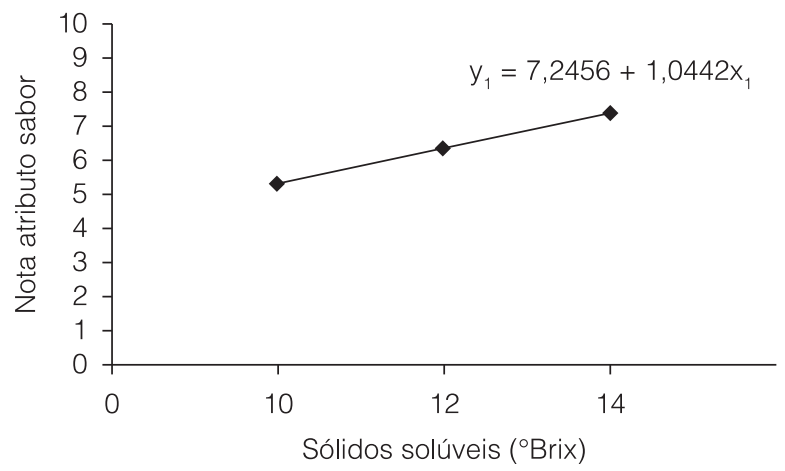

Figura 4. Efeito dos diferentes teores de sólidos solúveis no sabor da bebida mista. 
Teste de aceitação de bebida mista de soja e amora

ULIANA, M.R. et al.

Tabela 8. Análise de variância para o resultado da análise sensorial impressão global.

\begin{tabular}{lrccc} 
Causa de variação & GL & SQ & F & Pr $>$ F \\
Blocos & 1 & 0,05 & 0,56 & 0,48 \\
Proporção EHS/SA (P) & 2 & 0,49 & 2,68 & 0,13 \\
Sólidos solúveis (B) & 2 & 5,89 & $32,05^{*}$ & 0,00 \\
Interação P × B & 4 & 0,28 & 0,77 & 0,57 \\
Resíduo & 8 & 0,73 & - & - \\
Total & 17 & 7,46 & - & - \\
\hline
\end{tabular}

*Significativo.

Tabela 9. Análise de regressão para os sólidos solúveis, referente à impressão global.

\begin{tabular}{lrccc}
\multicolumn{1}{c}{$\begin{array}{c}\text { Causa de } \\
\text { variação }\end{array}$} & GL & SQ & F & $\begin{array}{c}\text { Coef. } \\
\text { determ. }\end{array}$ \\
Sólidos solúveis (B) & 1 & 5,87 & 59,02 & 0,99 \\
Resíduo & 16 & 1,59 & - & - \\
Total & 17 & 7,46 & - & - \\
\hline
\end{tabular}

A Equação 5 e a Figura 5 representam o modelo.

$y_{i}=5,1050+0,6992 x$

em que: $x_{i}=$ sólidos solúveis $i ; y_{i}=$ resposta à análise sensorial global (nota) em função dos teores de sólidos solúveis i.

A Figura 5 mostra que existiu uma relação direta das notas atribuídas pelos provadores com a doçura da bebida, dentro da faixa de Brix estudada.

Examinando-se as médias das notas da análise sensorial para a impressão global da bebida produzida (Tabela 3), pode-se observar que o grupo de provadores "não gostou; nem desgostou" (médias entre 5,6 e 6,0) das bebidas produzidas com 10 "Brix "gostou ligeiramente" (médias entre 6,4 e 6,7) das com $12{ }^{\circ}$ Brix e "gostou regularmente" (médias entre 6,8 e 7,4) das bebidas com $14^{\circ}$ Brix.

Felberg et al. (2004), estudando bebidas formuladas com EHS e castanha-do-brasil (escala hedônica estruturada de nove pontos), encontraram resultados inferiores aos deste estudo para a aceitação das bebidas, com notas entre 4,8 a 5,7 (dependendo da quantidade de EHS e de castanha-do-brasil formuladas).

Rodrigues (2003), estudando bebidas de EHS e polpa de pêssego, relatou notas entre 5,39 e 6,59 (teste de escala hedônica não estruturada de nove pontos) para a impressão global. Esse mesmo autor também observou que o aumento da doçura interfere diretamente na impressão global das bebidas, assim como aconteceu com o atributo sabor.

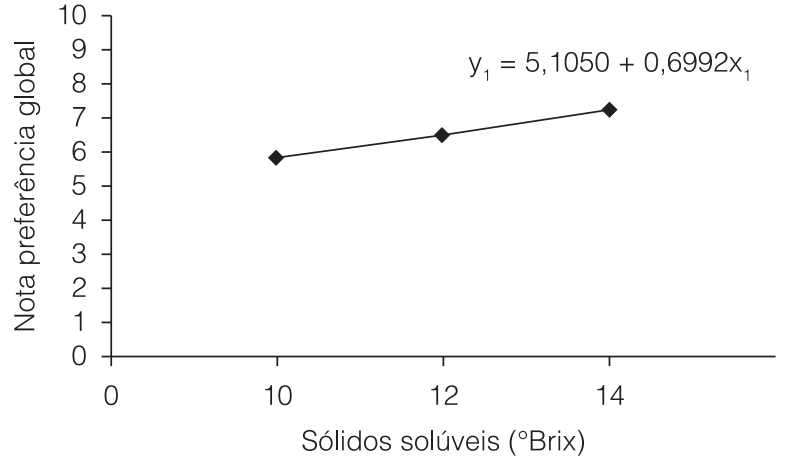

Figura 5. Efeito dos diferentes teores de sólidos solúveis na impressão global da bebida mista.

\section{Conclusões}

Os objetivos deste trabalho foram alcançados e, a partir dos resultados, pode-se concluir que:

- Todas as bebidas mistas, independentemente das suas formulações (sólidos solúveis e proporção EHS/SA), foram aprovadas pela equipe de provadores, em todos os atributos e na impressão global;

- O aumento da doçura das bebidas, dentro da faixa estudada, influenciou positivamente as notas para o atributo sabor e para a impressão global, havendo uma relação direta entre as notas e a doçura das bebidas.

\section{Agradecimentos}

Ao Conselho Nacional de Desenvolvimento Científico e Tecnológico (CNPq) e à Fundação de Amparo à Pesquisa do Estado de São Paulo (FAPESP).

\section{Referências}

ALIMENTOS funcionais. Food Ingredients, São Paulo, n. 9, p. 26-42, 2000.

BRANCO, I. G.; TEIXEIRA, A. M. ; RIGO, M. ; BEZERRA, J. R. M. V. ; COUTINHO, M. R.; ARGANDONA, E. J. S. ; BASTOS, R. Avaliação da aceitabilidade sensorial de uma bebida à base de extrato hidrossolúvel de soja, polpa de morango e sacarose. Revista Ciências Exatas e Naturais, Guarapuava, v. 9, n. 1, p. 129-141, 2007

BRASIL. Ministério da Agricultura, Pecuária e Abastecimento. Decreto $n^{\circ} 6.871$, de 04 de junho de 2009. Regulamenta a Lei n 8.918, de 14 julho de 1994. Dispõe sobre a padronização, a classificação, o registro, a inspeção, a produção e a fiscalização de bebidas. Diário Oficial da República Federativa do Brasil, Brasília, DF, 5 jun. 2009. Disponível em: <http://extranet. agricultura.gov.br/sislegis-consulta/consultarLegislacao. do?operacao=visualizar\&id=20271 >. Acesso em: 20 jul. 2009. 
Teste de aceitação de bebida mista de soja e amora

ULIANA, M.R. et al.

BRASIL. Ministério da Saúde. Agência Nacional de Vigilância Sanitária. Métodos Físico-Químicos para Análise de Alimentos. 4. ed. Brasília, DF, 2005. 1018 p.

CARRÃO-PANIZZI, M. C.; MANDARINO, J. M. G. Soja: Potencial de Uso na Dieta Brasileira. Londrina: Embrapa-CNPSo, 1998. (Documento, n. 113).

EMBRAPA. Soja na Alimentação. Disponível em: <http://www. cnpso.embrapa.br/soja_alimentacao/index.php>. Acesso em: 14 jul. 2008a.

EMBRAPA. Soja na Alimentação: Benefícios para a Saúde. Disponível em: <http://www.cnpso.embrapa.br/soja_ alimentacao/index.php?pagina=6>. Acesso em: 14 jul. 2008b.

FELBERG, I.; DELIZA, R.; GONÇALVES, E. B.; ANTONIASSI, R.; FREITAS, S. C.; CABRAL, L. C. Bebida mista de extrato de soja integral e castanha-do-brasil: caracterização físicoquímica, nutricional e aceitabilidade do consumidor. Alimentos e Nutrição, Araraquara, v. 15, n. 2, p. 163-174, 2004.

GOMES, F. P. Curso de Estatística Experimental. 6. ed. Piracicaba: Nobel, 1976. 430 p.

GUERREIRO, L. Dossiê Técnico: Produtos de Soja. Rio de Janeiro: Rede de Tecnologia do Rio de Janeiro - REDETEC, Serviço Brasileiro de Respostas Técnicas - SBRT, 2006. 25 p.

HASSIMOTTO, N. M. A. Atividade Antioxidante de Alimentos Vegetais: Estrutura e Estudo de Biodisponibilidade de Antocianinas de Amora Silvestre (Morus sp.). 2005. 159 f. Tese (Doutorado em Ciências dos Alimentos)-Faculdade de Ciências Farmacêuticas, Universidade de São Paulo, São Paulo, 2005.

KAWAGA, A. (Ed.). Standard Table of Food Composition in Japan. Tokyo: University of Nutrition for Woman Publishing Division, 1995. p. 104-105.

KRONES. Sucos: consumo da bebida à base de soja aumenta no Brasil. Boletim Eletrônico da Krones S/A, n. 6, 2002. Disponível em: <http://www.krones.com.br/Boletim/Edicao6/materia6.htm>. Acesso em: 18 abr. 2008.

LIU, K. Soybeans. Gaithersburg: Aspen Publishers, 1999. 532 p.

LIU, K. Soybeans Chemistry Technology and Utilization. 2. ed. New York: Chapman \& Hall, 1997. 532 p.
MACLEOD, G.; AMES, J.; BETZ, N. L. Soy flavor and its improvement. Critical Review in Food Science and Nutrition, v. 27, n. 4, p. 219-400, 1988. http://dx.doi. org/10.1080/10408398809527487

MERCALDI, J. C. Desenvolvimento de Bebida a Base de “Leite" de Soja Acrescida de Suco de Graviola. 2006. 53 f. Dissertação (Mestrado em Alimentos e Nutrição, Ciência dos Alimentos)-Faculdade de Ciências Farmacêuticas, Universidade Estadual Paulista, Araraquara, 2006.

MORAIS, A. A.; SILVA, A. L. A Soja: Suas Aplicações. Rio de Janeiro: Medsi, 1996. 259 p.

RODRIGUES, R. S. Caracterização de Extrato de Soja Obtido de Grãos, Farinha Integral e Isolado Protéico Visando à Formulação e Aviliação Biológica (em Coelhos) de Bebida Funcional à Base de Extrato de Soja e Polpa de Pêssegos. 2003. 177 f. Tese (Doutorado em Tecnologia de Alimentos)Faculdade de Engenharia de Alimentos, Universidade Estadual de Campinas, Campinas, 2003.

RODRIGUES, R. S.; GOZZO, A. M.; MORETTI, R. H. Comportamento reológico de extratos de grãos, farinha integral e isolado protéico de soja. Boletim do CEPPA, Campinas, v. 21, n. 2, p. 367-378, 2003.

STATISTICAL ANALISYS SYSTEM INSTITUTE - SAS. Statistical Analysis System. versão 8. Cary: The SAS Institute, 2001.

SOARES JUNIOR, M. S.; BASSINELLO, P. Z.; CALIARI, M.; VELASCO, P.; REIS, R. C.; CARVALHO, W. T. Bebidas saborizadas obtidas de extratos de quirera de arroz, de arroz integral e de soja. Ciência e Agrotecnologia, Lavras, v. 34, n. 2, p. 407-413, 2010. http://dx.doi.org/10.1590/S141370542010000200019

TORRES-PENARANDA, A. V.; REITMEIER, C. A. Sensory descriptive analysis of soymilk. Journal of Food Science, Malden, v. 66, n. 6, p. 352-356, 2001. http://dx.doi. org/10.1111/j.1365-2621.2001.tb11345.x

TORRES-PENARANDA, A. V.; REITMEIER, C. A.; WILSON, L. A.; FEHR, W. R.; NARVEL, J. M. Sensory characteristics of soymilk and tofu made from lipoxygenase-free and normal soybeans. Journal of Food Science, Malden, v. 63, n. 6, p. 1084-1087, 1998. HTTP://dx.doi.org/10.1111/j.1365-2621.1998.tb15860.x 